\title{
The effect of post-fixation olecranon lengthening on range of motion of the elbow: a cadaveric study
}

\author{
Khai Phang Wong ${ }^{*}$ and James Chung Hui Tan
}

\begin{abstract}
Background: Principles of fixation of comminuted olecranon fractures include anatomical reduction of the articular surface and restoration of ulnohumeral joint motion. However, comminution sometimes may not permit anatomical fixation of fracture fragments, resulting in inadvertent olecranon lengthening after plate fixation. The aim of our study is to investigate the relationship between olecranon lengthening following plate fixation and loss of elbow extension.

Materials and methods: Transverse olecranon osteotomies were performed on 8 cadaveric elbows. The osteotomy sites were then fixed with olecranon plates. Lengthening of the osteotomy sites were simulated by placement of $2 \mathrm{~mm}, 4 \mathrm{~mm}, 6 \mathrm{~mm}$ and $8 \mathrm{~mm}$ blocks. Lateral view photographs of the elbows were taken after each degree of lengthening. These photographs were then printed and measurements of elbow extension were performed with a goniometer with average values taken. The measurements were tabulated and statistical analysis performed to determine the relationship between degree of elbow extension loss and amount of olecranon lengthening.
\end{abstract}

Results: Average values of each degree of lengthening (at $2 \mathrm{~mm}, 4 \mathrm{~mm}, 6 \mathrm{~mm}$ and $8 \mathrm{~mm}$ ) were taken and compared with the baseline measurement (at $0 \mathrm{~mm}$ ). Cluster analysis showed that for every increment in osteotomy length of $2 \mathrm{~mm}$, there is a corresponding increase of $0.79^{\circ}$ of elbow extension loss ( $p<0.01,95 \%$ confidence level $\left.0.55^{\circ}-1.03^{\circ}\right)$.

Conclusion: Lengthening of olecranon by increments of $2 \mathrm{~mm}$ correlates positively with loss of elbow extension. This shows that inadvertent intra-operative olecranon lengthening post-fixation may result in limited range of motion. However, it is reassuring to know that the small degree of extension loss may not translate to functional limitation.

Keywords: olecranon plating, olecranon lengthening, comminuted fractures, elbow extension, osteotomy, cadaveric study

\section{Background}

Olecranon fractures constitute about $10 \%$ of all upper extremity fractures [1]. These fractures usually occur around the fifth decade of life and frequency increases with age reaching a peak during the seventh decade [2]. There is equal gender distribution, with a similar age-related increase [2]. Various classification systems

*Correspondence: khaiphang.wong@mohh.com.sg

Department of Orthopaedic Surgery, Khoo Teck Puat Hospital, 90 Yishun Central, Singapore 768828, Singapore

Level of evidence: Level $\mathrm{V}$ have been described, with the Mayo classification most commonly used by surgeons as it provides a guide to treatment. It is based on displacement, stability and comminution of the fracture fragments [3]. Type II and III injuries usually require surgical treatment.

Plate fixation is the preferred method of surgical fixation in fractures with comminution and bone loss, providing a stable construct with a low rate of hardware removal and allowing early functional rehabilitation with good union rates and clinical outcomes [4-9].

Loss of elbow extension is one of the most commonly reported complications of olecranon plating $[5,6$, original author(s) and the source, provide a link to the Creative Commons licence, and indicate if changes were made. The images or other third party material in this article are included in the article's Creative Commons licence, unless indicated otherwise in a credit line to the material. If material is not included in the article's Creative Commons licence and your intended use is not permitted by statutory regulation or exceeds the permitted use, you will need to obtain permission directly from the copyright holder. To view a copy of this licence, visit http://creativecommons.org/licenses/by/4.0/. The Creative Commons Public Domain Dedication waiver (http://creativecommons.org/publicdomain/zero/1.0/) applies to the data made available in this article, unless otherwise stated in a credit line to the data. 
9-15], potentially leading to poor functional outcomes. Extension deficit can be attributed to various causes. We believe that inadvertent olecranon lengthening during surgery is an under-reported cause.

The aim of this study is to determine the relationship between olecranon lengthening and loss of elbow extension. We hypothesize that olecranon lengthening leads to limitation of full elbow extension and potentially results in adverse outcomes. To test this hypothesis, a cadaveric study was conducted.

\section{Materials and methods}

\section{Specimens}

8 fresh cadaveric elbows ( 4 males and 4 females, mean age 74 years, with a range from 61 to 98 years) were obtained from Science Care Inc, Phoenix, Arizona, United States of America. The use of human cadaveric specimens for this study was approved by the local ethics committee. All cadaveric elbows did not have preexisting deformities or prior dissections. The specimens were kept in a storage fridge at a standard temperature. The individual specimens were then taken out for thawing one day prior to the conduct of the experiment.

\section{Measurement landmarks}

Drill bits were inserted into the humerus and the ulna at standardized locations for measurements $(5 \mathrm{~cm}$ and $10 \mathrm{~cm}$ from the tip of the olecranon, and $5 \mathrm{~cm}$ and $10 \mathrm{~cm}$ from the ulna styloid respectively). These were then tagged with red rubber bands as surrogates for the axes of the humerus and forearm (Fig. 1).

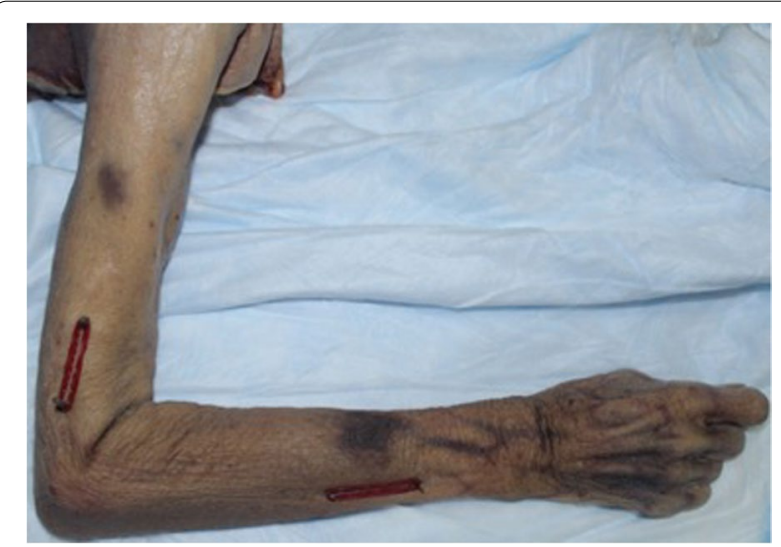

Fig. 1 Drill bits inserted 5 and $10 \mathrm{~cm}$ from the tip of the olecranon and 5 and $10 \mathrm{~cm}$ from the ulna styloid as surrogate for measurements of longitudinal axes of the humerus and forearm respectively

\section{Approach}

A standard posterior midline incision was used, starting proximal to the tip of the olecranon extending to the proximal aspect of the ulna. The triceps tendon was split at its insertion to accommodate the plate. The proximal ulna was then exposed. The specimens were then fixed with a 2.7/3.5 VA-LCP proximal olecranon plate (Synthes, Oberdorf, Switzerland) (Fig. 2). Two $2.7 \mathrm{~mm}$ locking screws were used to fix the proximal fragment and one $3.5 \mathrm{~mm}$ cortical screw was used to secure the plate to the ulna shaft.

\section{Osteotomy}

A transverse osteotomy is made at the lowest point of the trochlear notch, which is identified with the aid of a needle (Fig. 3). A small incision was made to expose the osteotomy site, taking care to preserve as much capsule and adjacent ligaments as possible.

\section{Measurements}

Olecranon lengthening was simulated by placing blocks of varying thickness $(2 \mathrm{~mm}, 4 \mathrm{~mm}, 6 \mathrm{~mm}$ and $8 \mathrm{~mm}$ ) into the osteotomy site (Fig. 4). The cadaveric elbows were

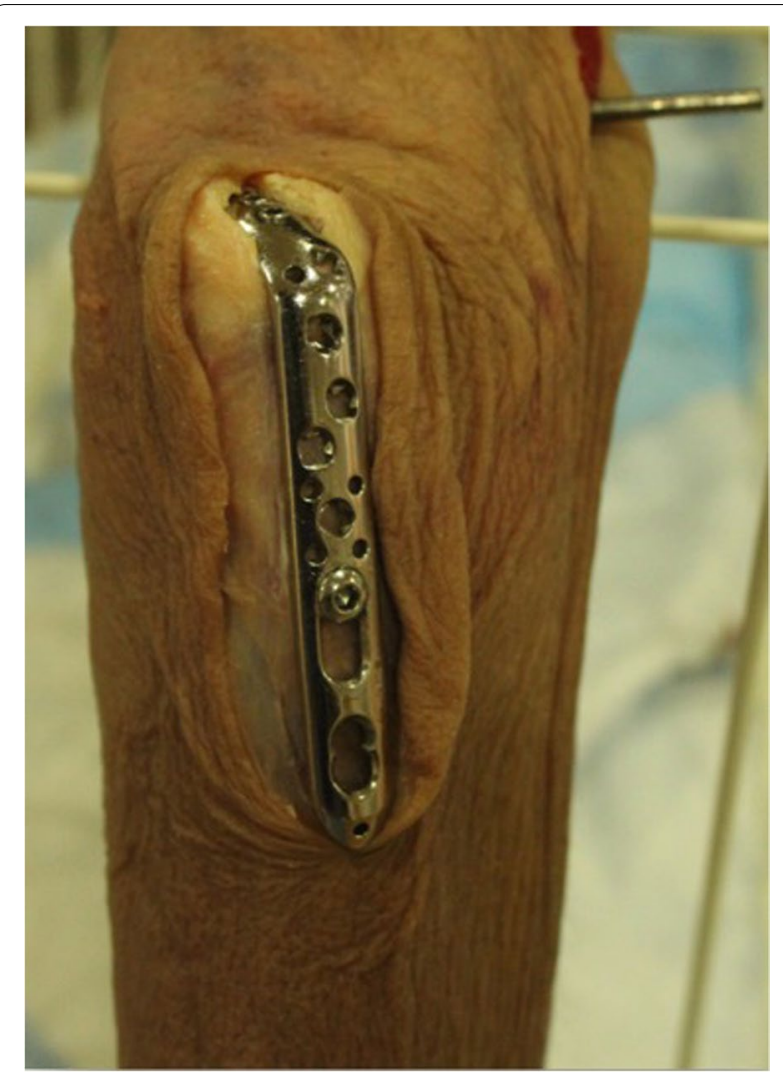

Fig. 2 The proximal ulna is exposed and fixed with a proximal olecranon plate 


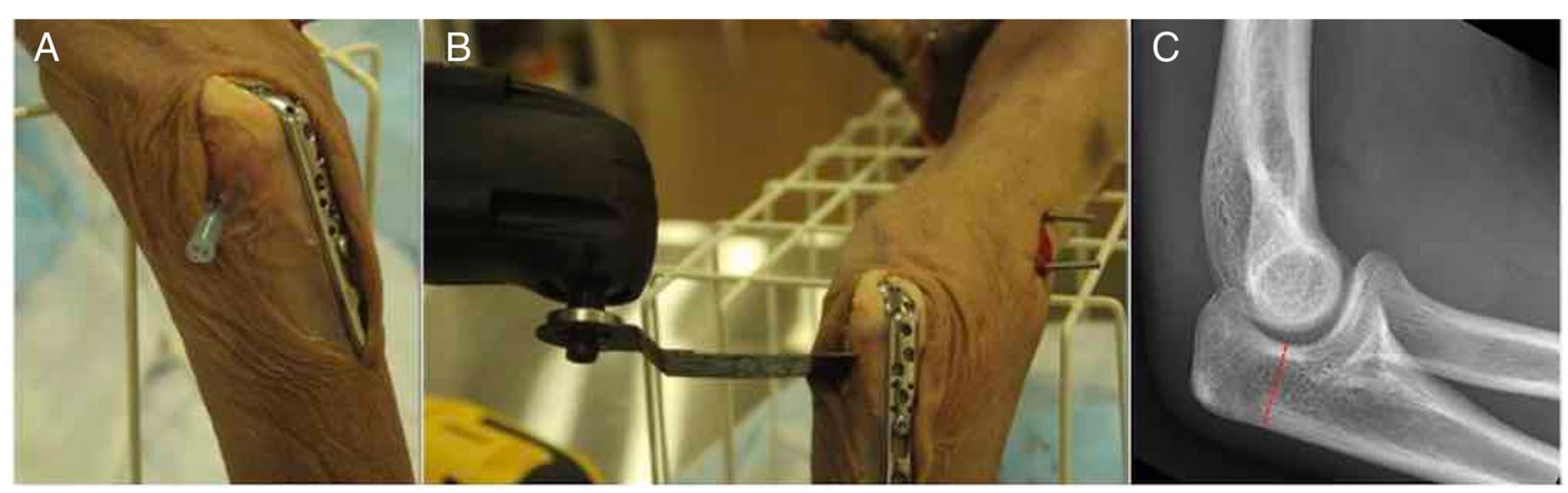

Fig. 3 Lowest point of trochlear is marked with needle (A). Osteotomy is performed at the marked point (B). Radiograph demonstrating location of osteotomy (C)

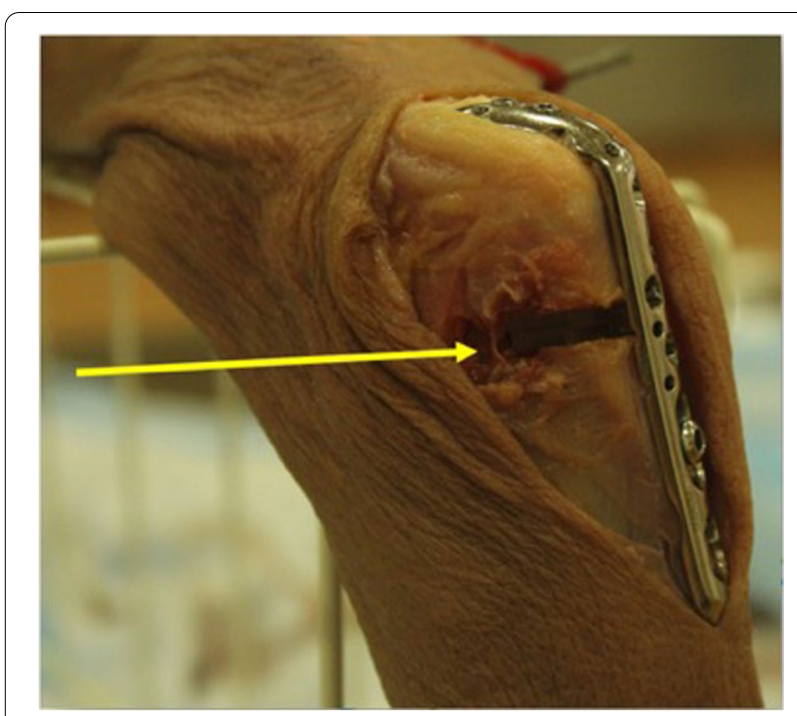

Fig. 4 Olecranon lengthening simulated by placing blocks of varying thickness into the osteotomy site

positioned such that the humerus was vertical and the elbow was extended by the pull of gravity. Photographs were taken at baseline $(0 \mathrm{~mm})$ and at interval increments of $2 \mathrm{~mm}$ (Fig. 5). The measurement at $0 \mathrm{~mm}$ was taken with the plate fixed and osteotomy performed, but without any blocks inserted. The photographs were then printed and measurements were done using a goniometer. To improve measurement accuracy, multiple photographs were taken at each increment and an average of the measurements was obtained. Equipment used was standardized for all 8 cadaveric specimens.

\section{Data analysis}

The average measurements for elbow extension (in degrees) at $2 \mathrm{~mm}, 4 \mathrm{~mm}, 6 \mathrm{~mm}$ and $8 \mathrm{~mm}$ were obtained for each cadaver and subtracted from the baseline $(0 \mathrm{~mm})$. Cluster analysis was performed with Stata IC Version 13.1 (StataCorp, Texas, U.S.) using the linear mixed effects model. The data was entered into tables and analysis was performed with the commands "xtmixed angle" (representing degree of extension deficit) and "osteo" (representing amount of osteotomy). Data was also plotted on graph using Microsoft Excel (Microsoft, Washington, U.S.A.).

\section{Results}

Table 1 shows the various degrees of extension deficits for various osteotomy lengths in each of the 8 cadavers. As we had 8 different cadavers each with different sets of data, we used the linear mixed effects model to allow for clustering of data, with each cadaver analysed as a cluster.

We found that in each of the cadavers, an increment in the osteotomy length generally results in an increase in the amount of extension deficit. Cluster analysis showed that for every increment in osteotomy length of $2 \mathrm{~mm}$, there is a corresponding increase of $0.79^{\circ}$ of elbow extension loss, with a p value of $>0.01$ and a $95 \%$ confidence level from $0.55^{\circ}$ to $1.03^{\circ}$. Fig. 6 shows a graphic representation of the linear regression relationship between osteotomy length and elbow extension deficit.

\section{Discussion}

The goals of surgical treatment in olecranon fractures are to restore articular congruity and joint stability for optimal bone healing, so as to allow early mobilization to achieve a pain-free functional elbow with good range of motion. Loss of elbow function can cause significant disability and adversely affect daily activities, work and recreational activities.

Tension band wiring has been shown to provide stable fixation with a good union rate in non-comminuted 


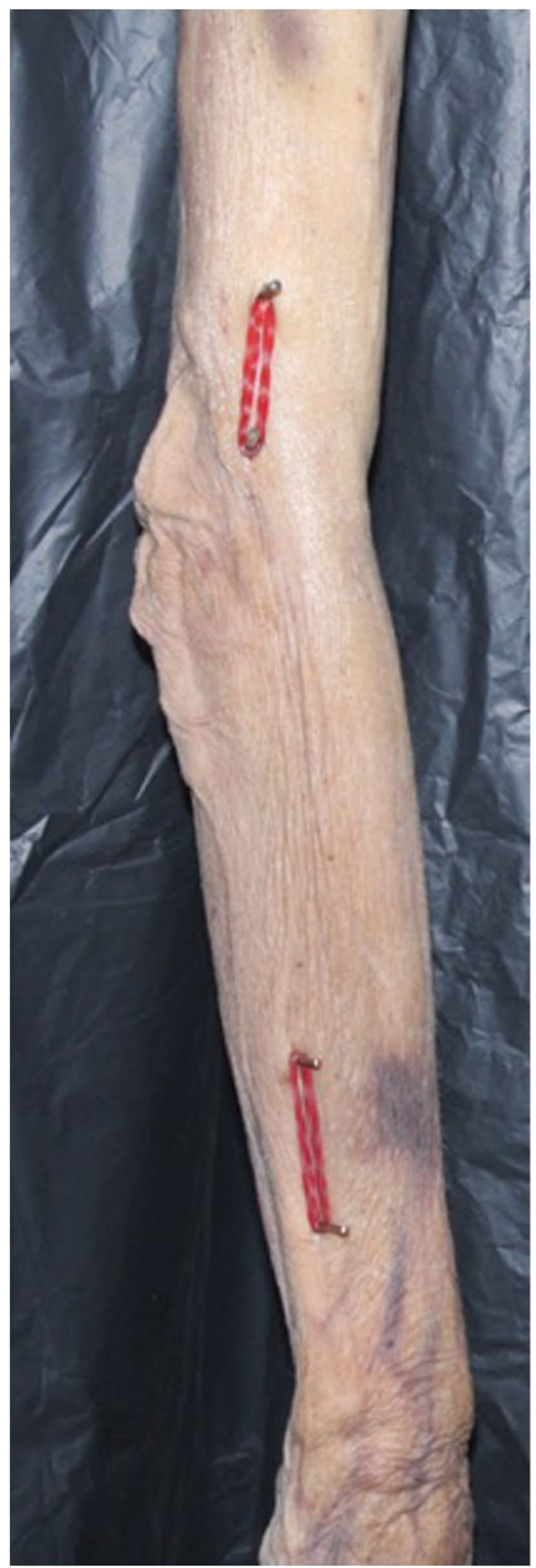

Fig. 5 The cadaveric elbows were positioned with the humerus vertical the elbow extended by the pull of gravity. Photographs were taken at baseline $(0 \mathrm{~mm})$ and at interval increments of $2 \mathrm{~mm}$ olecranon fractures with transverse configurations [16]. However, tension-band constructs in comminuted olecranon fractures may cause failure in compression due to subchondral bone comminution [4]. This causes the fracture fragments to collapse, leading to a narrowed surface for olecranon articulation and poor tracking [17]. In a mechanical study conducted by Fyfe et al, while tension-band wiring afforded adequate rigidity in models with transverse osteotomies, a significantly more stable fixation was achieved by plate fixation in more comminuted fractures [18]. Also, initiating early movement after tension band wiring may cause problems in comminuted fractures with bone loss [5]. Plate fixation has become standard treatment for comminuted olecranon fractures, and various clinical and biomechanical studies have reported favourable results, good functional scores and satisfactory range of motion $[4-9,15]$.

The popularization of posterior plating in comminuted olecranon fractures has also led to extensive research about its adverse consequences. The most common reported complication following plate fixation of comminuted fractures is loss of elbow extension [5, 6, 9-15]. Various studies have reported extension deficits ranging from $9.5^{\circ}[10]$ to greater than $30^{\circ}[6,12]$.

In 2016, De Giacomo et al reported that the most common deficiency in patients after olecranon plating was lack of full elbow extension [14]. In his study of 163 patients, $39 \%$ of patients lacked at least $10^{\circ}$ of extension compared to the contralateral limb, with a higher incidence in open fractures, comminuted fractures and fractures with diaphyseal extension. These patients were also found to have higher Disabilities of the Arm, Shoulder and Hand (DASH) scores (i.e. more severe disability) than their counterparts who achieved full elbow extension.

The exact etiology behind loss of terminal elbow extension after olecranon plate fixation has been poorly described in the literature. Hak and Golladay [19] found that loss of elbow motion was worse in patients with concomitant fractures of the radial head, capitellum, coronoid or Monteggia fracture-dislocations. Anderson et al [5] postulated that loss of elbow extension was due to the proximal aspect of the plate sitting in close proximity to the triceps mechanism. However, it is evident that extension deficits still persist even after modernization of the olecranon plate allowing more anatomical fit to the proximal ulna.

The proximal ulna comprises the coronoid and the olecranon process, making up the saddle-shaped ellipsoid articular surface of the sigmoid notch [20]. The olecranon process plays an integral role in maintaining passive stability of the elbow joint as serial resection of the olecranon results in a linear reduction in stability $[20,21]$. 
Table 1 Table showing degrees of elbow extension deficits at various osteotomy lengths in 8 cadaveric elbows

\begin{tabular}{lllllllll}
\hline $\begin{array}{l}\text { Osteotomy } \\
\text { length }(\mathbf{m m})\end{array}$ & \multicolumn{2}{l}{ Extension deficit (degrees) } & & & & \\
\cline { 2 - 8 } & Cadaver $\mathbf{1}$ & Cadaver $\mathbf{2}$ & Cadaver 3 & Cadaver 4 & Cadaver 5 & Cadaver 6 & Cadaver 7 & Cadaver 8 \\
\hline 2 & 0.25 & 4.25 & 1.25 & 2.00 & 2.50 & 0.00 & 1.75 & 0.00 \\
4 & 2.25 & 4.50 & 1.25 & 2.25 & 5.00 & 6.00 & 2.25 & 5.50 \\
6 & 2.50 & 5.00 & 2.75 & 2.50 & 6.25 & 7.00 & 3.50 & 6.25 \\
8 & 5.75 & 7.50 & 3.25 & 2.75 & 6.75 & 8.00 & 10.25 & 8.00 \\
\hline
\end{tabular}

\section{Effect of Osteotomy Length on Extension Deficit}

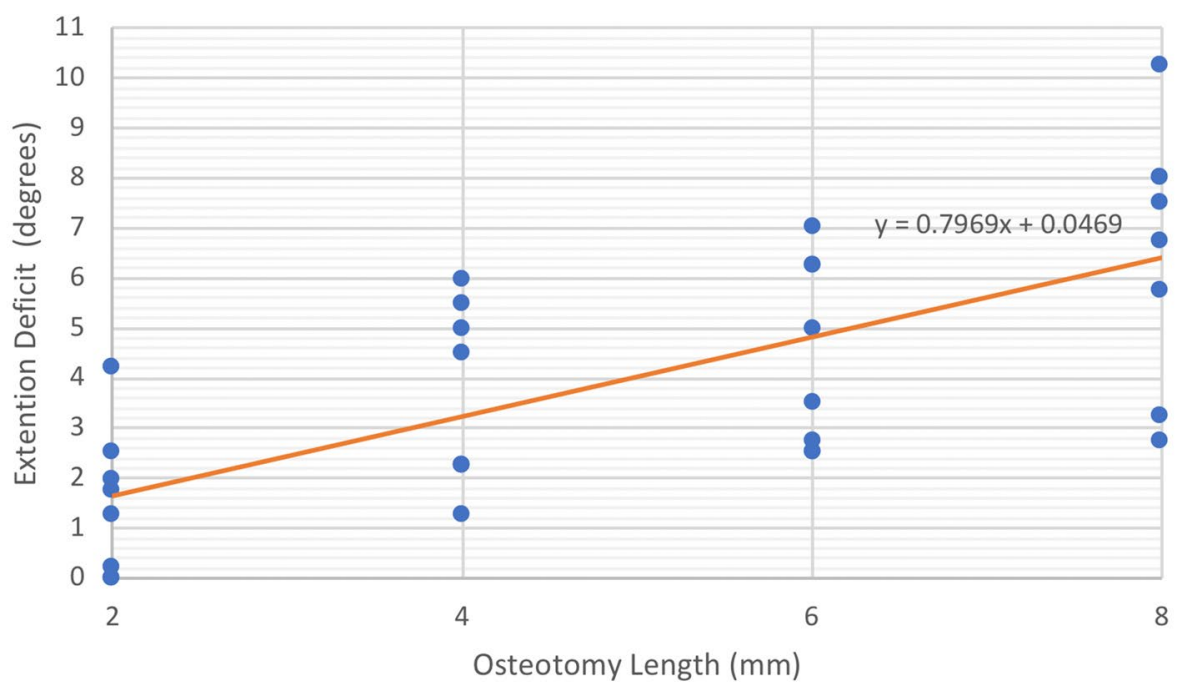

Fig. 6 Linear regression analysis of relationship between osteotomy length (in $\mathrm{mm}$ ) and elbow extension deficit (in degrees)

The midpoint from the coronoid process to the tip of the olecranon is covered by a transverse area devoid of cartilage [22]. Over-compression of this area during fracture reduction is undesirable as it may lead to a narrowed trochlear fossa and an incongruent radius of curvature [17]. We believe the converse is also true in the case of lengthening.

Normal elbow range of motion is from $0^{\circ}$ to $150^{\circ}$ [20]. Morrey et al demonstrated that functional elbow range of motion ranges from $30^{\circ}$ to $130^{\circ}$ [23]. Fischer et al showed that elbow flexion and extension occurred around a centre of rotation involving an area of 2 to $3 \mathrm{~mm}$ in diameter at the trochlear [23]. During elbow extension, the olecranon fossa accommodates the olecranon process of the ulna. This articulation is lost in displaced fractures and also in comminuted fractures that are plated incorrectly resulting in advertent olecranon lengthening. This may ultimately result in limitation to full elbow extension.

Bailey et al in 2001 [4] emphasized the importance of restoring the normal anatomy of the trochlear notch, in particular the anterior and posterior facets of the olecranon. They also mentioned in their study that severe comminution may result in a gap between the facets and olecranon shortening does not affect the outcome as long as the contour of the olecranon notch is maintained. However, this has not been substantiated in their study. Some authors argue that loss of terminal flexion and extension are usually minor and functionally insignificant [16], but the degree of which were not specified. In 1987, Murphy et al [24] studied olecranon fractures and concluded that an articular displacement or mal-reduction greater or equal to $2 \mathrm{~mm}$ was associated with poorer results in terms of pain and range of motion. To our best knowledge, there have been very few studies in the current literature investigating the effects of olecranon lengthening following suboptimal olecranon fixation.

Our present study shows that lengthening of the olecranon at the articular surface has a positive correlation to loss of terminal elbow extension after fixation with an anatomical olecranon plate. We believe that in patients 
with severely comminuted fractures, improper plate placement or non-anatomic fracture reduction may result in inadvertent olecranon lengthening. If this lengthening is not recognized intraoperatively, this may result in postoperative limitation of terminal elbow extension. However, due to the relatively small degree of extension loss of $0.79^{\circ}$ for every $2 \mathrm{~mm}$ lengthening, it may be reassuring to know that this may not translate to functional limitation. We also note that in vivo, post-operative immobilization and rehabilitation protocols play important roles in determining extension loss, which we were unable to determine using our cadaveric study.

We recognize a few limitations of our present study. As with most cadaveric studies, other important factors that influence elbow movement such as blood supply, triceps and soft tissue integrity and healing response of the bone are not taken into account, and may be confounding factors. Many of the specimens are intrinsically contracted, which may affect degree of lengthening. We established a baseline measurement after performing the osteotomy and applying the plate without any extension blocks being placed, and took reference from this baseline measurement to compare with the subsequent ones after simulated lengthening.

We were also limited by a small sample size of 8 cadaveric elbows with no control group. Therefore, we used a linear mixed effects model to allow for clustering of data, with each cadaver analysed as a cluster. As standard error is small, cluster analysis makes our data achieve statistical significance.

A potential method to improve our result accuracy is to incorporate the use of fluoroscopy. Wadia et al [25] stated that the trochlear width as seen on the lateral view is the line that will be most affected in olecranon fractures and is the single most important parameter to be reconstructed. He studied 100 normal adult antero-posterior and lateral elbow radiographs and derived 3 measurement ratios to help determine a more accurate and reliable method to measure intra-operative olecranon length. Incorporating these measurements in our study would allow us to better quantify olecranon lengthening. We also advocate use of these fluoroscopic parameters intraoperatively to ensure adequate restoration of olecranon length, especially in cases of severe comminution.

\section{Conclusion}

In conclusion, our cadaveric study shows a significant association between olecranon lengthening in $2 \mathrm{~mm}$ increments up to $8 \mathrm{~mm}$ and loss of elbow extension. We believe that inadvertent olecranon lengthening following plate fixation is an under-reported cause of elbow extension deficit post-surgery. This usually results from nonanatomic reduction of fracture fragments in cases with severe comminution and bone loss. We advocate use of radiological parameters intraoperatively to ensure adequate restoration of olecranon length.

\section{Acknowledgements}

The authors acknowledge Associate Professor Yeo Tsin Wen, NTU Lee Kong Chian School of Medicine, Tan Tock Seng Hospital for his invaluable assistance with the data analysis and interpretation.

\section{Authors' contributions}

JCHT conceptualized the research question and the methodology, and obtained the grant required for the acquisition of the cadavers. KPW performed the osteotomies and the measurements on the cadaveric specimens, and was a major contributor in writing the manuscript. Both authors read and approved the final manuscript.

\section{Funding}

The authors received funding from the Alexandra Health Enabling Grant (AHEG) for the purchase of the cadavers and the equipment required for the conduct of the experiments.

\section{Availability of data and materials}

The datasets generated and/or analysed during the current study are not publicly available due to patient confidentiality but are available from the corresponding author on reasonable request.

\section{Declarations}

\section{Ethics approval and consent to participate}

National Healthcare Group (NHG) Domain Specific Review Board (DSRB) exemption was approved on 17 December 2020 (NHG DSRB Ref 2020/00943). All methods were carried out in accordance with relevant guidelines and regulations. Informed consent was obtained from all next of kin of the cadavers used.

\section{Consent for publication}

Not applicable

\section{Competing interests}

The authors declare that they have no competing interests.

Received: 22 July 2021 Accepted: 1 December 2021

Published online: 20 December 2021

\section{References}

1. Rommens PM, Kuchle R, Schneider RU, et al. Olecranon fractures in adults: factors influencing outcome. Injury. 2004;35:1149-57. https://doi.org/10. 1016/j.injury.2003.12.002.

2. Duckworth AD, Clement ND, Aitken SA, Court-Brown CM, McQueen MM. The epidemiology of fractures of the proximal ulna. Injury. 2012;43:343-6. https://doi.org/10.1016/j.injury.2011.10.017.

3. Morrey BF. Current concepts in the treatment of fractures of the radial head, the olecranon, and the coronoid. Instr Course Lect. 1995;44:175-85.

4. Bailey CS, MacDermid J, Patterson SD, King GJ. Outcome of plate fixation of olecranon fractures. J Orthop Trauma. 2001;15:542-8. https://doi.org/ 10.1097/00005131-200111000-00002.

5. Anderson ML, Larson AN, Merten SM, Steinmann SP. Congruent elbow plate fixation of olecranon fractures. J Orthop Trauma. 2007;21:386-93. https://doi.org/10.1097/BOT.0b013e3180ce831e.

6. Buijze GA, Kloen P. Clinical Evaluation of Locking Compression Plate Fixation for Comminuted Olecranon Fractures. J Bone Joint Surg Am. 2009;91(10):2416-20. https://doi.org/10.2106/JBJS.H.01419.

7. Buijze GA, Blankevoort L, Tuijthof GJ, Sierevelt IN, Kloen P. Biomechanical evaluation of fixation of comminuted olecranon fractures: one-third tubular versus locking compression plating. Arch Orthop Trauma Surg. 2010;130(4):459-64. https://doi.org/10.1007/s00402-009-0980-z. 
8. Erturer RE, Sever C, Sonmez MM, Ozcelik IB, Akman S, Ozturk I. Results of open reduction and plate osteosynthesis in comminuted fracture of the olecranon. J Shoulder Elbow Surg. 2011;20(3):449-54. https://doi.org/10. 1016/j.jse.2010.11.023.

9. Karlsson MK, Hasserius R, Karlsson C, Besjakov J, Josefsson PO. Fractures of the olecranon: a 15- to 25-year followup of 73 patients. Clin Orthop Relat Res. 2002;403:205-12.

10. Niglis L, Bonnomet F, Schenck B, Brinkert D, Di Marco A, Adam P, et al. Critical analysis of olecranon fracture management by pre-contoured locking plates. Orthop Traumatol Surg Res. 2015;101(2):201-7. https://doi. org/10.1016/j.otsr.2014.09.025.

11. Horne JG, Tanzer TL. Olecranon fractures: A review of 100 cases. J Trauma. 1981;21(6):469-72.

12. Holdsworth BJ, Mossad MM. Elbow function following tension band fixation of displaced fractures of the olecranon. Injury. 1984;16(3):182-7. https://doi.org/10.1016/0020-1383(84)90156-6.

13. Kiviluoto $O$, Santavirta S. Fractures of the olecranon: Analysis of 37 consecutive cases. Acta Orthop Scand. 1978;49(1):28-31. https://doi.org/10. 3109/17453677809005719.

14. De Giacomo AF, Tornetta P 3rd, Sinicrope BJ, Cronin PK, Althausen PL, Bray TJ, et al. Outcomes after plating of olecranon fractures: A multicenter evaluation. https://doi.org/10.1016/j.injury.2016.04.015.

15. Siebenlist S, Torsiglieri T, Kraus T, Burghardt RD, Stockle U, Lucke M. Comminuted fractures of the proximal ulna-preliminary results with an anatomically preshaped compression plate (LCP) system. Injury. 2010;41:1306-1. https://doi.org/10.1016/j.injury.2010.08.008.

16. Wolfgang G, Burke F, Bush D, Parenti J, Perry J, LaFollette B, et al. Surgical treatment of displaced olecranon fractures by tension band wiring technique. Clin Orthop Relat Res. 1987;224:192-204.
17. Veillette CJ, Steinmann SP. Olecranon fractures. Orthop Clin North Am 2008;39(2):229-36. https://doi.org/10.1016/j.ocl.2008.01.002.

18. Fyfe IS, Mossad MM, Holdsworth BJ. Methods of fixation of olecranon fractures. An experimental mechanical study. J Bone Joint Surg Br. 1985;67:367-72. https://doi.org/10.1302/0301-620X.67B3.3997942.

19. Hak DJ, Golladay GJ. Olecranon fractures: treatment options. J Am Acad Orthop Surg. 2000;8:266-75. https://doi.org/10.5435/00124635-20000 7000-00007.

20. Fornalski S, Gupta R, Lee TQ. Anatomy and biomechanics of the elbow joint. Tech Hand Up Extrem Surg. 2003;7(4):168-78. https://doi.org/10. 1097/00130911-200312000-00008.

21. An KN, Morrey BF, Chao EY. The effect of partial removal of proximal ulna on elbow constraint. Clin Orthop Relat Res. 1986;209:270-9.

22. Stormont TJ, An KN, Morrey BF, et al. Elbow joint contact study: comparison of techniques. J Biomech. 1985;18(5):329-36. https://doi.org/10.1016/ 0021-9290(85)90288-x

23. Cabanela ME, Morrey BF. Fractures of the proximal ulna and olecranon. In: Morrey BF, editor. The elbow and its disorders. 2nd ed. Philadelphia: WB Saunders; 1993. p 381-99

24. Murphy DF, Greene WB, Dameron TB Jr. Displaced olecranon fractures in adults: Clinical evaluation. Clin Orthop Relat Res. 1987;224:215-23.

25. Wadia F, Kamineni S, Dhotare S, Amis A. Radiographic measurements of normal elbows: clinical relevance to olecranon fractures. Clin Anat. 2007;20(4):407-10. https://doi.org/10.1002/ca.20431.

\section{Publisher's Note}

Springer Nature remains neutral with regard to jurisdictional claims in published maps and institutional affiliations.
Ready to submit your research? Choose BMC and benefit from:

- fast, convenient online submission

- thorough peer review by experienced researchers in your field

- rapid publication on acceptance

- support for research data, including large and complex data types

- gold Open Access which fosters wider collaboration and increased citations

- maximum visibility for your research: over $100 \mathrm{M}$ website views per year

At $\mathrm{BMC}$, research is always in progress.

Learn more biomedcentral.com/submissions 